\section{The Challenge of Long-term Participatory Repository Governance}

\author{
Lessons Learned for High Level \\ Radioactive Waste and Spent Fuel
}

\section{by Catharina Landström, University of East Anglia, and Jan-Willem Barbier, University of Antwerp}

\begin{abstract}
Voluntaristic siting procedures for deep geological repositories are becoming increasingly common; they reconfigure the relationship of repositories and society in ways that have implications for the long-term governance of these facilities. This paper identifies three challenges emerging in relation to this question: principles of monitoring, repository content, and facility closure. This paper discusses them in a comparison with similar challenges being addressed in Belgian partnerships founded to facilitate the siting and design of a low- and intermediate level short lived waste repository. The empirical exploration confirms the importance of securing stakeholder engagement throughout the repository lifecycle, for which there is a need to develop knowledge about how to encourage long-term democratic governance systems.
\end{abstract}

\section{Introduction}

Geological disposal was first proposed as the safe solution to the risk posed to human health and the environment by long-lived high level radioactive waste (HLW) and spent nuclear fuel (SNF) in the 1950s. Since then this idea has been developed by scientists, engineers and policy makers in the countries harbouring such hazardous waste. Universally adopted as the only viable final solution to the very long-term risk posed by these materials, geological disposal proved difficult to implement. So far no country has yet managed to open a repository, as a range of obstacles, including vigorous public opposition, have challenged implementation programmes. Such obstacles have forced changes in geological disposal programmes, most importantly with regard to the role of civil society in the siting of repositories.

In the late 1990 s and early 2000 s several countries devised new procedures for increased public participation in nuclear waste management. With regard to HLW/SNF geological disposal a few nations undertook radical policy revisions, halting their existing implementation programmes and appointing special bodies tasked with formulating new strategies involving the public in new ways (e.g. Canada and the UK). In many more countries public involvement was accommodated through changes in existing programmes (e.g. Sweden and Switzerland). Currently most national HLW/SNF geological disposal programmes involve public participation of some degree, ranging from local authorities having veto rights to reliance on local communities volunteering to host repositories. The increasing involvement of civil society in the siting and construction of geological disposal repositories for HLW/SNF brings with it new challenges and this paper discusses issues that might arise in the future concerning the governance and related innovations in view of transparency and societal follow-up of potential geological repositories, from the emplacement of waste begins to the final closure.

In addressing a possible future, in which one (or more) geological disposal facility may become operational, this discussion is speculative and in this it resembles discussions about the technical function of repositories during the emplacement and post closure phases. In contrast to the scientific and engineering projections of future developments we conduct a qualitative discussion drawing on social science research. Whether future events will play out in a fashion similar to what we envisage here is impossible to know. In spite of this the issue of repository governance deserves attention from policy makers, implementers and regulators.

Our reflections are based on the work done in the context of a European FP7 research project InSOTEC (http://www.insotec.eu/), and on addressing the question of long-term governance in the case of the Belgian Local Partnerships (see infra) in an action-research project financed by the Belgian radioactive waste management agency, ONDRAF/NIRAS.

\section{Voluntarism}

International consensus on isolation by geological barriers being the only way to ensure the safe disposal of HLW and SNF has evolved into dif- 
ferent national strategies, partly in processes attempting to overcome actual and anticipated civic and political opposition to the siting of geological repositories. The many failures to site repositories have brought about a realisation that geological disposal cannot be approached as a purely technical question, but must be considered as being both social and technical. This insight has prompted policy reconsiderations, sometimes leading to explicit breaks with the past and adoption of new strategies, in other cases to incorporation of novel ideas in existing programmes. In order to move the implementation of geological disposal closer several governments have adopted voluntaristic siting procedures, in which transparency and local communities' rights to influence are part of the framework from the outset.

Although not yet very advanced, most are in the initial stages of siting, these policies are presented as democratic and transparent, whether this will be the dominant perception if siting processes progress remains to be seen. Critical scrutiny of different national policy development processes cast doubt on the degrees of democracy and transparency in the new strategies (e.g. Durant, Stanley 2009). However, the voluntaristic policies differ from previous top-down programmes in very visible and politically significant ways and they demonstrate to civil society that geological disposal is now being implemented in a participatory way. Furthermore, in cases where progress is made after stronger engagement of local communities, potential host communities have formulated continuous transparency and follow-up as key conditions for implementation. This is for example the case in Östhammar, the municipality designated to host the Swedish spent nuclear fuel (e.g. Östhammars Kommun 2012).The details of voluntaristic siting strategies of HLW/SNF differ between nations, but in several cases a point of reference for their development is the "Belgian Partnerships" (CoRWM 2006).

The Belgian local partnerships were developed in order to site a low an intermediate level, short-lived waste (LLW/ILW) repository ${ }^{1}$. They were created in the wake of the failure of previous efforts, based solely on technical and geological parameters, and a brief attempt to determine socio-political feasibility applying the same techno- cratic, top-down rationale. The local partnerships were established to explicitly link the technical and socio-political feasibility studies together and to engage the concerned communities in this process. They are composed of people representing social, political or economic actors from their community. Local people thus became involved in co-designing the integrated surface repository concept, together with the national waste manager ONDRAF/NIRAS (Bergmans et al. 2006; Bergmans 2008; Barbier/Bergmans 2011).

\section{Three Key Challenges for Geological Repository Governance}

While making progress with siting implementers are finding that repository concepts developed in voluntaristic frameworks must satisfy demands arising from the fact that facilities are placed within the territory of local communities. Voluntaristic siting changes the cultural notion of geological disposal, from visions of repositories as geographically remote, in the middle of nowhere, to them becoming a community concern, even functioning as resources for local development. The reconfiguration of the relationship of repositories with society, which follows from voluntaristic siting, has implications for the longterm governance and related societal follow-up of geological disposal facilities.

In the context of the InSOTECproject some of the key remaining socio-technical challenges (i.e. calling for both social and technical innovations) with regard to high level radioactive waste management have been identified (Landström/ Bergmans 2012). Three of them are closely related to the long-term governance of radioactive waste repositories. Firstly, who will be able to call for changes to, or termination of, a repository programme if insurmountable technical or social obstacles would emerge? Secondly, if a facility is successfully built and operating, who is to decide on which waste it will eventually accept? Thirdly, when the emplacement of waste is nearing the planned upper limit, how will the decision about the closure of the facility be made? In the present paper these issues are elaborated in relation to the Belgian partnerships. Like Östhammar, they are in a situation where the site has been selected, and where the local community remains engaged 
in following up of the licence application process as a first step towards implementation of the repository. Although the time scales of LLW/ ILW and HLW/SNF disposal are different, we believe the identified issues are comparable and therefore the work that has been carried out by the Belgian local partnerships is a useful starting point for addressing long-term governance challenges in HLW/SNF disposal.

\section{Similar Challenges Emerging in Belgium}

The empirical findings elaborated in this section were gathered through participatory observations during working group meetings of both partnerships and planning meetings between the partnerships and ONDRAF/NIRAS, formal and informal contacts with concerned actors, analysis of written communications (minutes of meetings, reports, etc.), a series of in-depth interviews with partnership participants (fall 2010), and participation in a series of small workshops bringing together members of the local partnerships - building on their experiences - and technical experts from ONDRAF/NIRAS on the subject of monitoring for geological disposal for the European FP7 project MoDeRn ${ }^{2}$. The objective of these workshops was to assess if and how monitoring could be a part of governance around geological disposal.

Both local partnerships have been involved in the siting process since 1999/2000. After site selection in 2006, the partnerships remained involved in the detailed elaboration of the repository concept. Throughout their activity, both before and after siting, they touched on different issues related to the long-term governance of the planned repository, for example the followup of the monitoring programme. The long-term governance issue is one that has been given great attention throughout the partnerships' existence. Both local partnerships and ONDRAF/NIRAS have expressed the explicit intention of prolonging the participatory process as long as the waste repository exists (NIRAS 2010). That way, they want to assure that participation of the local public is possible at any given moment in time, whenever deemed necessary. Such an approach raises new questions, for example, about how to warrant public participation during the next 300 years. A possible challenge could be the loss of public knowledge about nuclear waste. So far, no "grand plan" has been proposed on how exactly to bring this about, even if this issue has been discussed almost since the beginning of the partnerships' activity. But by continuing their existence and putting up issues for future discussion, issues that are very similar to the challenges we identified for the long-term governance of HLW/ SNF disposal, the partnerships may gradually pave the path for long-term involvement.

\subsection{Principles of Monitoring}

The Belgian local partnerships have been stressing their interest in the monitoring programme of the LLW/ILW repository since the beginning of their existence. Subsequently, they were closely involved in the development of the monitoring programme during the design phase of the repository. What they considered crucial is the provision of a framework for interpretation, communication and action. This is where determination of responsibilities for the long term becomes an important issue. Who will execute the monitoring programme in the long term? Who will control the authority that is responsible for monitoring? Who will decide on actions if the monitoring programme detects anomalies?

The questions posed by the local partnerships in relation to monitoring pertain to a governance framework in view of the first challenge raised, namely the clarification of decision-making structures for geological repositories in the event of unanticipated events that would require intervention and remediation. The issue was also discussed in-depth in the MoDeRn workshop, in which people from the partnerships stressed the fact that monitoring is not useful unless remediation is an anticipated option. Although all participants agreed that it is impossible to foresee a governance framework that will last as long as the lifetime of the repository, and that it is very likely that future generations will alter this framework following their own knowledge, preferences and assumptions, they state that some guidelines must be followed when setting up a monitoring programme, including remediation possibilities. A first important principle suggested by the participants is the engagement of stakeholders through the entire monitoring cycle. This means assum- 
ing that there will be involvement not only during the determination of the monitoring programme, but also during the follow-up of the monitoring results and - more importantly - during the future phases when decisions about undertaking action or not become relevant. In the opinion of the workshop participants, engagement is the ongoing interaction between all different stakeholders: the exchange of information, the hearing of external experts, the possibility of posing critical questions and the mutual decision making process involving stakeholders and waste manager.

The workshop participants also discerned some issues that are very difficult to resolve. First, they recognized that a third party, a mediator, is necessary if waste manager and stakeholders do not agree on a decision. However, it remains unclear who could embody this function. Second, they found that in the long term, financing becomes a major problem. It is almost impossible to estimate how much the solution of problems in a repository could cost, but it is very unlikely that the waste producers will exist as long as the repository. We can note that with regard to HLW/SNF the "polluter pays" principle, currently adopted in most national programmes can be undermined by the longevity of the risk posed. Finally, the workshop participants were concerned about the difficulty of constructing sustainable frameworks for participation that can last over time, taking into consideration that societies will change and knowledge may be lost, interests are likely to change, as will cultures. The participants agreed that formulating solutions for future problems is difficult, and that people in the future will most likely be in a better position to solve them. Nevertheless, prolonging stakeholder engagement throughout the lifecycle of the repository could, according to them, be the starting point for answering those issues.

\subsection{Repository Content}

A second governance issue concerns who will decide on which waste and how much of it should be accepted, if a facility is successfully constructed. Waste categorization is not fixed and may very well change during the period of repository construction and operation. For example, in the UK or France, the answer to the question whether civilian and military waste should be disposed separately, or not may change over time. Other factors impacting waste character and amount are the reprocessing of SNF. Transparent procedures for making decisions about what can go into a repository and how to decide on possible repository expansion need to be in place before issues arise.

In Belgium, the waste manager has opted to divide the waste into three categories. Category A is low- and intermediate level short-lived waste. Category B is low- and intermediate level longlived waste and category $\mathrm{C}$ is high level waste. The boundary between low- and intermediate level waste is a contact dose pace of 5 millisievert per hour. The boundary between short and long-lived waste is less clear and depends on the time frame active control of the waste is needed: a few hundred years in the case of category A waste opposed to a more than a few hundred years for category B and C waste (NIRAS 2010). In other countries, other categories are used, leading to a wide variety of classifications worldwide (Landström/ Bergmans 2012). The variability in waste classification demonstrates the importance of social context; the physical characteristics of the waste are the same in all countries and the IAEA (2009) supplies an exhaustive typology for all kinds of radioactive waste, still waste denominations and categorizations vary between countries. Throughout the process of designing the Belgian LLW/ ILW repository, waste categorization and related issues were treated multiple times when considering the "filling up strategy", indicating where different types of waste will be stored inside the repository. From the beginning, it was clear that the repository should only host category A waste (this is reflect in the name of the project: cAt). However, what exactly was understood as category A waste was somewhat less clear, as a discussion in the general assembly of one of the local partnerships pointed out (STOLA 2008). From the outset it was communicated to the local partnerships that this comprised all short-lived waste of low- and intermediate radiation levels. But that proved quite a mouthful and immediately a convenient short-hand emerged talking of low-level and short-lived waste. Discussing the "filling up strategy" later on in the process confronted people with a less clear-cut reality, in stating that the most active waste will be stored in the middle, so 
that other types of waste could act as buffer. This meant there were significant differences in activity levels to be taken into account. Some discussion followed about the extent to which different waste streams could be fully characterised. For some historical waste this was particularly difficult. Partnership members were therefore particularly concerned over the presence of long-lived fractions in the short- and medium level waste, as minutes of various working group meetings show.

Before the repository will be put into operation, the Belgian regulatory agency, Federal Agency for Nuclear Control (FANC), will review and issue permits for the filling up strategy (FANC 2009). Thereafter, during the filling up of the repository, the partnerships have expressed their intent to review the operations of the waste manager, together with FANC. They wish to pay particular attention to the characteristics of the waste going in and whether it corresponds with the features described in the strategy. However, it is not yet clear how these review activities will take place and whether they will involve the local community, given the high level of technical knowledge needed to carry them out.

Although there are large differences between low-level short-lived waste and high-level long-lived waste, we think it is possible to extrapolate some findings. Firstly, that the technicality of the issue requires expert knowledge in developing procedures and strategies. Secondly, that the procedures need to facilitate participation and accountability. Partnership members have stressed, not only the importance of including local stakeholders in discussions on and approval of procedures and strategies, but also of giving them the possibility to oversee the waste manager during the operation of the repository and review actual practices in order to ensure that they conform to the accepted strategy. This implies some sort of participation during the entire operational phase of the disposal facility.

\subsection{Facility Closure}

The third governance issue identified is the decision about the closure of the facility, once the emplacement of waste has reached the planned limit. Since closure of filled up geological repositories is not foreseen within the next 100 to 150 years, there is no way of knowing how decision making will be organized on the international, national or local level. However, knowing that, if repositories become operational, decisions about closure inevitably have to be made, not addressing the issue would be a serious oversight. In the traditional, "first generation" plans for geological disposal programmes, it was implicit that national governments would decide on closure when informed by experts that it was appropriate. In the new voluntaristic programmes embracing participatory constellations this can no longer be taken for granted. We may not know how decision making will be organised in 150 years, but we do know that the programmes involving local participation already differ from what was envisioned in past policies. Hence, we envision the value of a repository "constitution" communicating the ethos of participatory, transparent and democratic decision making. The question is who will take the decision to close the facility or to further emplacement, particularly as there may be actors - for example nuclear power companies - interested in pushing the limits. A reparticipatory governance structures needed during the closure phase? If this is the case, is it possible to protect and codify public engagement? In France, for example, it has been stated in law, that the closure of a geological repository facility can only be authorised by law, and such a law, according to current regulations, must be subjected to prior public debate. ${ }^{3}$

Even in the Belgian case of LLW/ILW closure of the repository is not foreseen within the next 50 to 80 years (STORA 2004). The time frame might not be completely the same, but the issue that has to be dealt with is similar: how to guarantee democratic decision making without being able to forecast societal evolution? The answer to this question rests on two pillars.

First, that the closure process has been elaborated in detail during the design phase of the repository. Since both local partnerships have been involved in the design process, they were able to express concerns regarding the initial proposals by the waste manager. These concerns were taken into account in the further development of the closure phase. In the end, a closure process which consists not only of a formal decision about closure, but also of the filling up of an inspec- 
tion gallery ${ }^{4}$ and the construction of a permanent cover - was proposed by the waste manager and agreed upon by the local partnerships (NIRAS 2010). However, it is far from certain that the closure process will be executed as stated in the cAtmaster plan, written in 2010. Not only technical knowledge about covering a repository, but also society and cultural values are likely to change over the coming decades. ONDRAF/NIRAS and the local partnerships recognised this issue and admitted that a higher level of participation might be needed again during the closure phase, compared to the operational phase. Therefore, a commitment was made by the waste manager and the (local) authorities to ensure that opportunities for local actors to actively participate in future decisions regarding closure are provided (NIRAS 2010). Although no concrete suggestions have been made about the format of this active participation, the intent is to ensure the local partnerships remain active during the entire time of repository operations. That way, the specific culture, knowledge and practices needed to organize effective participation can evolve over time and will not have been lost when the closure of the repository and the corresponding licensing phase arrive.

Critical to the strategy of keeping the local partnerships "alive", are the creation of a local fund and the construction of a communication centre (NIRAS 2010). Both local partnerships will have active roles in the daily operations of the communication centre and the spending of the local fund. Although this is not a guarantee for continued existence of the local partnerships in the same form as they exist today, it is a backbone around which both partnerships can formulate their own goals, assignments and structures in order to assure their own functioning in the long term.

\section{Concluding Remarks}

The invention and development of the geological disposal solution to the risk posed by HLW and SNF can be understood to also express distrust in society's ability to handle such long-term extreme hazards. Burying the waste deep underground in a remote location delegates the safekeeping to the near unchangeable geology and the predictable behaviour of engineered barriers. However, it proved impossible to find sites "outside" of socie- ty as political and civil society opposition brought the first generation of implementation policies to a halt. Policy re-thinks have acknowledged the inescapability of society and devised strategies with various degrees of local community involvement.

The second-generation HLW/SNF geological disposal strategies have moved implementation to a new stage, but they have also generated new challenges. In this paper we have focussed on issues arising in relation to long-term repository governance. While it may be felt that it is impossible to control these issues, as social organisation and cultural values may change beyond recognition even during the century of repository operation, we argue that these issues need consideration. Our argument is based on an understanding of geological disposal as a socio-technical combination, as embodying a new configuration of technology and society (Landström/Bergmans 2012).

Approached as socio-technical combinations geological disposal facilities draw on established technoscientific knowledge and practices, but it is also important to use the knowledge and experience we have regarding society. In this paper we used the experience in one case where a LLW/ILW surface repository has been developed in collaboration between waste manager and local citizens. We argued that some issues regarding governance arising in the deliberations on this type of repositories were relevant for HLW/SNF disposal facilities. Following three themes: monitoring, content and closure, we could flesh out our initially abstract questions with empirical content.

The empirical excursion confirmed our belief that these issues are important and need to be addressed. One idea emerging from our reflections is to look at the formal constitutions underpinning the operations of democratic nation states. One example would be the US, where society and culture have changed beyond recognition since the 18th century, but the separation of powers inscribed in the 1787 constitution remains a cornerstone. At the time when the US constitution was written the federal democratic nation was a new governance invention and nobody could know if it would last. Governance systems are not created because we can predict that they will work, but because we hope that they may guide. When we bring the social into the technical we need to also 
mobilise and enhance the knowledge and experience about how to encourage long-term democratic governance systems.

\section{Notes}

1) Two such partnerships exists today: STORA in Dessel; http://www.stora.org/en/content/storayour-eyes-and-ears, and MONA in the neighbouring municipality of Mol; http://www.monavzw. be/; in Dutch only.

2) A series of four workshops was organized between 15/12/2011 and 24/05/2012. Between ten and 14 volunteers from the local partnerships participated in every workshop, together with two technical experts from ONDRAF/NIRAS and two moderators/reporters from the University of Antwerp. The first workshop started with a free association around the notion of "monitoring" for geological disposal. Gradually, this notion was elaborated in more detail, while at the same time discussing the participants own experiences with monitoring in the LLW/ILW project. For more information on MoDeRN see http://www.modern-fp7.eu and the contribution by Bergmans/Elam et al. in this issue.

3) Loi $n^{\circ} 2006-739$ du 28 juin 2006 de programme relative à la gestion durable de matières et déchets radioactifs: Article 12

4) A space of about 1 meter is foreseen underneath the entire repository in order to be able to check for leakages or other anomalies with a robot (NIRAS 2010).

\section{References}

Barbier, J.; Bergmans, A., 2011: Participatie na de locatiekeuze. Uitdagingen voor de lokale partnerschappen STORA en MONA; vandaag en in de toekomst. Antwerpen

Bergmans, A., 2008: Meaningful Communication Among Experts and Affected Citizens on Risk: Challenge or Impossibility? In: Journal of Risk Research 11 (2008), pp. 175-193

Bergmans, A.; Van Steenberge, A.; Verjans, G., 2006: CARL Country Report - Belgium; hhttp://webhost. ua.ac.be/carlresearch/docs/20070914152818OZSV. pdf (download 27.11.12)

CoRWM-Committee on Radioactive Waste Management, 2006: Managing our Radioactive Waste Safely. CoRWM's Recommendations to Government. CoRWM Doc 700; http://corwm.decc.gov.uk/assets/corwm/post-nov $\% 2007 \% 20 \mathrm{doc} \% 20$ store/documents/reports $\% 20$ to $\% 20$ government $/$ nov $\% 20$ and $\% 20 \mathrm{dec} \% 20$ 2007/700\%20-\%20corwm\%20july\%202006\%20rec- ommendations \%20to\%20government.pdf (download 12.12.12)

Durant, D.; Stanley, A., 2009: An Official Narrative: Telling the History of Canada's Nuclear Waste Management Policy Making. In: Durant, D.; Johnson, G.F. (eds.): Nuclear Waste Management in Canada. Critical Issues, Critical Perspectives. Vancouver

FANC - Federal Agency for Nuclear Control, 2009: The Surface Repository Project for Category A Waste. Brussels; http://www.fanc.fgov.be/nl/page/hetproject-oppervlakteberging-van-afval-van-categoriea/1220.aspx (download 12.12.12)

IAEA - International Atomic Energy Agency, 2009: Classification of Radioactive Waste. Vienna

Landström, C.;Bergmans, A., 2012: Socio-Technical Challenges to Implementing Geological Disposal: A Synthesis of Findings from 14 Countries; https://docs. google.com/viewer? $\mathrm{a}=\mathrm{v} \&$ pid $=$ sites\&srcid $=\mathrm{aW}$ zb3R 1Yy5ldXxpbnNvdGVjfGd4OjMzZDV1YTQ3Y2Y5Z DFiNmY (download 22.1.13)

NIRAS - Nationale instelling voor radioactief afval en verrijkte splijtstoffen, 2010: The cAt Project in Dessel. A Long-term Solution for Belgian Category A Waste. Brussel; http://www.niras-cat.be/downloads/ cAt_masterplanENG.pdf (download 31.11.12)

Östhammars Kommun-Slutförvarsenheten,2012:Verksamhetsberättelse 2011; http://www.osthammar.se/ Documents/Slutforvar/Verksamhetsber\%c3\%a4ttelse/ Verksamhetsber \%c3\%a4ttelse $\% 202011, \% 20$ s lut f \% c $3 \%$ b 6 rvarsorganis a ti on en, $\% 20$ $\%$ c3\%96sthammars\%20kommun.pdf (download 31.11.12)

STOLA, 2008: General Assembly - Report 20-032008. Dessel

STORA - Studie- en Overleggroep Radioactief Afval in Dessel, 2004: Belgian Low-level and Short-lived Waste: Does it Belong in Dessel? An Integrated Disposal Project With Technical and Social Implications. Dessel

\section{Contact}

Dr. Catharina Landström

School of Environmental Sciences

University of East Anglia

Norwich Research Park

Norwich NR4 7TJ, United Kingdom

Phone: +44 (0) 1603 - 592970

Email: C.Landstrom@uea.ac.uk 